\title{
TRANSFER OF THERMAL FLUCTUATIONS THROUGH THE BUILDING PARTITION FORMED BY PERIODIC COMPOSITE MATERIAL*
}

\author{
Dorota Kula ${ }^{凶}$, Łukasz Wodzyński \\ Institute of Civil Engineering, Warsaw University of Life Sciences - SGGW
}

\begin{abstract}
The paper presents examples of thermal fluctuations imposed on the average physical field, which are intensively suppressed by a building partition formed of a periodic two-phase composite. This intense attenuation applies not only to exponential attenuation, until recently identified with the so-called composite boundary effect behaviour, but also mute oscillatory damping, which next to exponential damping, most often accompanies the boundary effect behaviour. The considerations were made using the parabolic equation of thermal conductivity as a starting point leading to the equivalent reformulation, but they can be easily transferred, e.g. to the area of linear elasticity and other physical phenomena occurring in composites. Considerations of this paper can be taken into account in the design of rooms that should effectively protect precision electronic devices against the harmful effects of external fluctuations in physical fields.
\end{abstract}

Key words: effective heat conduction, boundary effect behaviour, building partition, average temperature field

\section{INTRODUCTION}

The analytical description of the composite boundary effect behaviour due to both displacement and temperature fields is closely related to the presence in the equations of thermoelasticity of components with the second spatial derivative and concerns both fields affected by the spatial divergence operator - kinematic displacement field (or deformation in linear elasticity) and temperature field. Consequently, the description of the boundary effect behaviour is qualitatively similar regardless of the physical field to which it relates. Unless the description applies to a pair of physical conjugate fields. Considerations are limited to the composite phenomenon of thermal conductivity described by Fourier conductivity law. The basics of tolerance modelling, thanks to which the equations used in this work could be obtained, are developed by Woźniak and Wierzbicki (2000). The mathematical theory of the basics of tolerance modelling techniques was developed by Ostrowski (2017). Surface localized description of heat conduction is used to debark the thermal model of the boundary effect phenomenon from the parabolic thermal conductivity equation (cf. Kula, 2014; Kula \& Wierzbicki, 2019; Wierzbicki, 2019). The surface localized heat transfer equations (HTEs) can be rewritten in the form:

\footnotetext{
${ }^{*}$ Text was formatted in one-column page style due to complexity of the article. 


$$
\begin{gathered}
\langle c\rangle \dot{u}-\nabla^{T}\left(\langle k\rangle \nabla u+\left\langle k \nabla^{T} \varphi^{p}\right\rangle a_{p}\right)=-\langle b\rangle \\
\lambda^{2}\left(A_{c}^{p q} \dot{a}_{q}-\nabla_{z}^{T} A_{k}^{p q} \nabla_{z} a_{q}\right)+2 \lambda s^{p q} \nabla_{z} a_{q}+\{k\}^{p q} a_{q}=\left(L_{a}^{\lambda}[u]\right)^{p}
\end{gathered}
$$

holds in the materially homogeneous parts of the region $\Omega$ occupied by the considered composite for:

$$
\{k\}^{p q}=\left\langle\nabla_{y}^{T} \varphi^{p} k \nabla \varphi^{q}\right\rangle, \quad 2 s^{p q}=\left\langle\nabla_{y}^{T} \varphi^{p} k \varphi^{q}\right\rangle-\left\langle\nabla^{T} \varphi^{q} k \varphi^{p}\right\rangle
$$

and for $A_{c}^{p q} \equiv\left\langle\varphi^{p} c \varphi^{q}\right\rangle, A_{k}^{p q} \equiv\left\langle\varphi^{p} k \varphi^{q}\right\rangle$ taken in Eq. (1b) as coefficients at the highest, second-order derivatives. Term $\left(L_{a}^{\lambda}[u]\right)^{p}$ being the RHS of Eq. (1b) includes all averaged terms including thermal sources. In Eq. (1): $u$ and $a_{p}$ denote the average temperature field and Fourier amplitudes, respectively, symbols $k, c$ stand for the effective conductivity matrix and specific heat fields, respectively. Moreover, Eq. (1) includes scale parameter equal to the characteristic length dimension $\lambda$ of the repetitive cell divided by the composite characteristic length dimension of region occupied by the composite. Here and in the sequel $\nabla_{y}$ is the projection of gradient operator $\nabla \equiv\left[\partial_{1}, \partial_{2}\right.$, $\left.\partial_{3}\right]^{T}$ onto periodicity directions and formula $\nabla_{y}+\nabla_{z} \equiv \nabla$ define projection $\nabla_{z}$ of gradient operator onto directions perpendicular to directions of periodicity. Summation convention holds in the whole volume of the paper.

\section{THERMAL BOUNDARY EFFECT PHENOMENON}

The homogeneous part of the Eq. (1b), i.e.:

$$
\lambda^{2}\left(A_{c}^{p q} \dot{a}_{q}-\nabla_{z}^{T} A_{k}^{p q} \nabla_{z} a_{q}\right)+2 \lambda s_{\text {suff }}^{p q} \nabla_{z} a_{q}+\{k\}_{\text {surf }}^{p q} a_{p}=0
$$

is free from external influences represented by the expression $L_{a}^{\lambda}[u]$ and is usually considered a model of the boundary effect phenomenon. This equation is qualitatively similar to the analogous equation of the boundary effect obtained in the tolerance averaging technique (TAT) but differs from it by the number of equations and form of coefficients expressed by Fourier basis $\varphi^{p}, p=1,2, \ldots$, taken in Eq. (3) as an infinite number of shape function.

In the paper, attention will be focused on the stationary boundary effect phenomenon which, consists of two types of damping of fluctuations transferred through the composite - exponential damping and oscillatory damping strictly connected with the real and imaginary parts of complex roots of algebraic equations characteristic for Eq. (3). Hence the simplest properties of the composite boundary effect phenomenon can be investigated for the two-dimensional composite medium with one-directional periodicity. In this case, the homogeneous part (3) of the surface localized HTEs (1) reduces to the infinite system of ordinary differential equations

$$
A_{k}^{p q} \frac{d^{2} a_{p}}{d z^{2}}-2 \lambda s^{p q} \frac{d a_{q}}{d z}-\{k\}^{p q} a_{q}=0
$$

For homogeneous periodicity, in which the period is constant, Eq. (4) has constant coefficients. In the paper Eq. (4) is treated as a model of the boundary effect phenomenon. In the case when we have to examine the boundary effect phenomenon for a single Fourier fluctuation $\varphi=\varphi^{p}$ for a fixed integer $p$ and hence term $2 \lambda s^{p q} d a_{q} / d z$ vanish. Hence the transport of a single Fourier fluctuation across the region occupied by the composite does not meet the oscillatory reaction, i.e. it results $s^{p q}=0$ for any positive indices $p, q$. Moreover, in this case the intensity of the related exponential damping meets local maximum (cf. Kula, 2019). 
The aim of this paper is $1^{\circ}$ to check if exponential damping meet local maximum in more complicated cases, in which the pair of Fourier fluctuations are transferred through the composite, and $2^{\circ}$ to investigate pairs of Fourier fluctuations which are harmless to devices situated in rooms with walls formed by composite walls, i.e. for which damping intensity for oscillatory rotations is sufficiently large. Typical Fourier basis consists of both left and right even, as well as odd impulses defined by (cf. Fig. 1)

$$
\begin{aligned}
& f_{L}(v, y)=\left\{\begin{array}{l}
\frac{\lambda}{2}\left\{1-\alpha_{1}\left[1+\cos \left(2 \pi v\left(\frac{y}{\lambda \eta^{\mathrm{I}}}+1\right)\right)\right]\right\} \text { for }-\lambda \eta^{\mathrm{I}} \leq y \leq 0 \\
\frac{\lambda}{2}\left\{1-\alpha_{1}\left[1+\cos \left(2 \pi v\left(\frac{\bar{y}}{\lambda \eta^{\mathrm{I}}}+1\right)\right)\right]\right\} \text { for } 0 \leq y \leq \lambda \eta^{\mathrm{II}}, \bar{y}=0
\end{array}\right. \\
& f_{R}(v, y)=\left\{\begin{array}{l}
\frac{\lambda}{2}\left\{1-\alpha_{2}\left[1+\cos \left(2 \pi v\left(\frac{\bar{y}}{\lambda \eta^{\mathrm{II}}}-1\right)\right)\right]\right\} \text { for }-\lambda \eta^{\mathrm{I}} \leq y \leq 0, \bar{y}=0 \\
\frac{\lambda}{2}\left\{1-\alpha_{2}\left[1+\cos \left(2 \pi v\left(\frac{y}{\lambda \eta^{\mathrm{II}}}-1\right)\right)\right]\right\} \text { for } 0 \leq y \leq \lambda \eta^{\mathrm{II}}
\end{array}\right. \\
& f_{O D D}(v, y)=\left\{\begin{array}{l}
-\frac{\lambda}{2} \cos \left((2 v-1) \pi\left(\frac{y}{l^{\mathrm{I}}}+1\right)\right) \text { for }-l^{\mathrm{I}} \leq y \leq 0 \\
-\frac{\lambda}{2} \cos \left((2 v-1) \pi\left(\frac{y}{l^{\mathrm{II}}}-1\right)\right) \text { for } 0 \leq y \leq l^{\mathrm{II}}
\end{array}\right.
\end{aligned}
$$

Formulas (5) involves two-phased composites with $0 y$ - direction taken as periodicity direction and $\eta_{\mathrm{I}}=l^{\mathrm{I}} /\left(l^{\mathrm{I}}+l^{\mathrm{II}}\right), \eta_{\mathrm{II}}=l^{\mathrm{II}} /\left(l^{\mathrm{I}}+l^{\mathrm{II}}\right)$, taken as saturations of the first and the second components, respectively. Parameter $v$ takes positive integer values, while $\alpha_{1}=1 /\left(\eta_{\mathrm{I}}+2 \eta_{\mathrm{II}}\right), \alpha_{2}=1 /\left(\eta_{\mathrm{I}}+2 \eta_{\mathrm{II}}\right)$ are chosen, so that $\left\langle f_{1}\right\rangle=\left\langle f_{2}\right\rangle=0$ is taken as the normalized condition. Figure 1 illustrates the impulses defined by Eqs. (5) and (13) for $v=1$. Replacements $\varphi_{L}(v, y)=\lambda^{-1}\left[f_{L}(v, y)+\alpha f_{R}(v, y)\right], \varphi_{R}(v, y)=\lambda^{-1}\left[f_{L}(v, y)-\alpha f_{R}(v, y)\right]$ and $\varphi_{O D D}(v, y)=f_{O D D}(v, y)$, taken under orthogonality condition $\left\langle\varphi^{p} k \varphi^{q}\right\rangle=0, p, q=1,2, \ldots$, valid for $p \neq q$ and $\alpha^{2}=\left\langle f_{L}(v, y) k f_{L}(v, y)\right\rangle /\left\langle f_{R}(v, y) k f_{R}(v, y)\right\rangle$, produce new orthogonal impulses $\varphi_{L}(v, y)$ and $\varphi_{R}(v, y)$ usually named Fourier amplitudes. Obviously, lexicographic numbering order $\varphi^{p}=\varphi_{L}(v, y)$ for $p=1+3(v-1)$, $\varphi^{p}=\varphi_{R}(v, y)$ for $\varphi^{p}=2+3(v-1), \varphi^{p}=\varphi_{O D D}(v, y)$ for $p=3+3(v-1)$ should be introduced.

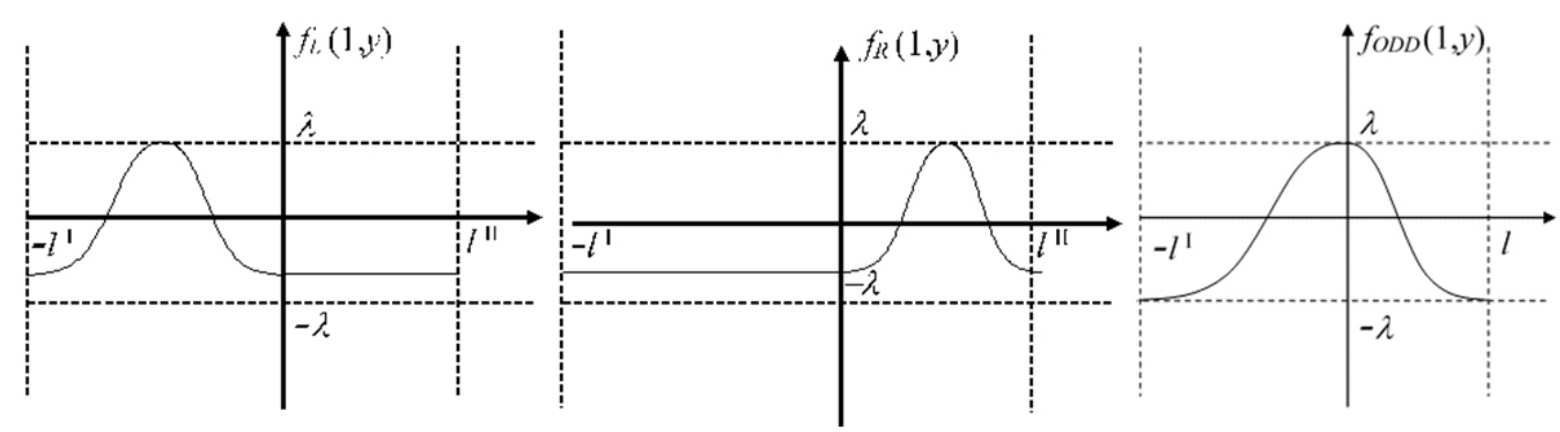

Fig. 1. Even $f_{L}, f_{R}$ and odd $f_{O D D}$ temperature impulses 


\section{TRANSPORT OF A SINGLE ODD FOURIER FLUCTUATION}

For isotropic conductor Eq. (4) reduces to the second-order ordinary differential equation

$$
\lambda^{2} \gamma\langle k\rangle \frac{d^{2} a_{1}}{d z^{2}}-c\langle k\rangle_{H} a_{1}=0
$$

for $k$ used as a scalar (not as a matrix) conductivity and $\gamma\langle k\rangle=A_{k}^{11}=\left\langle\varphi f_{O D D}(v, y) \varphi_{O D D}(v, y)\right\rangle$, $c\langle k\rangle_{H}=\{k\}^{11}=\left\langle k\left(d \varphi_{O D D}(v, y) / d y\right)^{2}\right\rangle, \gamma=0.125, c=0.125(2 v-1)^{2} \pi^{2}$, and for

$$
\langle k\rangle=\eta_{\mathrm{I}} k_{\mathrm{I}}+k_{\mathrm{II}} \eta_{\mathrm{II}},\langle k\rangle_{H}=\frac{\left(\eta_{\mathrm{II}} k_{\mathrm{I}}+k_{\mathrm{II}} \eta_{\mathrm{I}}\right)}{\eta_{\mathrm{I}} \eta_{\mathrm{II}}}
$$

obviously in Eq. (6). Algebraic equation $\lambda^{2}\langle k\rangle \gamma r^{2}-c\langle k\rangle_{H}=0$, characteristic for differential Eq. (6), has two real roots and hence exponential and rotational intensities defined as real and imaginary parts of the characteristic equation are given by

$$
\omega_{\text {exp }}=r_{1,2}= \pm \sqrt{\frac{1}{\lambda^{2}} \frac{\langle k\rangle_{H}}{\langle k\rangle} \frac{c}{\gamma}}, \omega_{r o t}=0
$$

It has been analytically proved (Kula, 2019) that for any saturation $\eta=\eta^{\mathrm{I}}$ exponential intensit $\omega_{\text {exp }}=\omega_{\text {exp }}(\eta, k)$ meet local maximum for a certain parameter $k \equiv k_{2} / \mathrm{k}_{1}$. The lack of the imaginary part $\omega_{\text {rot }}$ of the root $r=\omega_{\text {exp }}+j \omega_{\text {rot }}, j^{2}=-1$, indicates that rotational intensity value is equal to zero, i.e. a single odd impulse does not oscillate. The graphs of the exponential intensity $\omega_{\text {exp }}=\omega_{\text {exp }}(\eta, k)$ of a single odd impulse as a function of two arguments $\eta$ and $k$ is illustrated in Figure 2 .

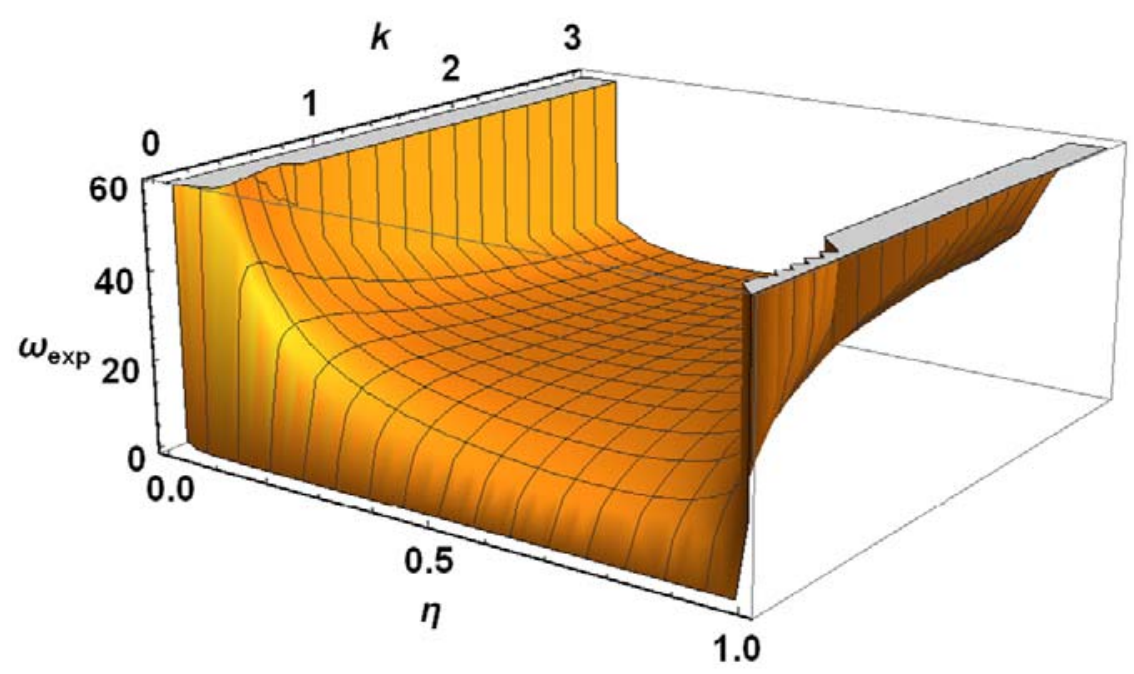

Fig. 2. Exponential intensity for a single impulse $f_{O D D}$ 


\section{TRANSPORT OF FOURIER FLUCTUATION PAIRS}

Linear combination $a_{1} \varphi^{1}\left(v_{1}, y\right)+a_{2} \varphi^{2}\left(v_{2}, y\right)$ of impulses $\varphi^{1}$ and $\varphi^{2}$ transferred through the composite will be investigated. If $\varphi^{1}$ and $\varphi^{2}$ are Fourier orthogonal amplitudes and assuming the absence of heat sources amplitudes $a_{1}$ and $a_{2}$ should satisfy the matrix model equations for boundary effect behavior:

$$
\lambda^{2} A_{K} \frac{d^{2} a}{d z^{2}}-2 \lambda S_{K} \frac{d a}{d z}-\frac{\langle k\rangle_{H}}{\langle k\rangle}\{A\}_{K} a=0
$$

For $a \equiv\left[a_{1}, a_{2}\right]^{T}$ and matrix coefficients

$$
A_{K}=\left[\begin{array}{cc}
\alpha_{1} & 0 \\
0 & \alpha_{2}
\end{array}\right], S_{K}=\left[\begin{array}{cc}
0 & \beta \\
-\beta & 0
\end{array}\right],\{A\}_{K}=\left[\begin{array}{cc}
\gamma_{1} & 0 \\
0 & \gamma_{2}
\end{array}\right]
$$

with $\quad \alpha_{1}=\left\langle k \varphi_{1} \varphi_{1}\right\rangle /\langle k\rangle, \quad \alpha_{2}=\left\langle k \varphi_{2} \varphi_{2}\right\rangle /\langle k\rangle, \quad \gamma_{1}=\left\langle k\left(d \varphi_{1} / d y\right)^{2}\right\rangle /\langle k\rangle, \quad \gamma_{2}=\left\langle k\left(d \varphi_{2} / d y\right)^{2}\right\rangle /\langle k\rangle \quad$ as well as $\beta=\left(\left\langle k \varphi_{1} d \varphi_{2} / d y\right\rangle-\left\langle k \varphi_{2} d \varphi_{1} / d y\right\rangle\right) /\langle k\rangle$. Under boundary conditions written in the form $a(0)=a^{0} \equiv\left[a_{1}(0)\right.$, $\left.a_{2}(0)\right]^{T}, a(\delta)=a^{\delta} \equiv\left[a_{1}(\delta), a_{2}(\delta)\right]^{T}$ Eq. (9) leads to the solutions obtained by Kula (2016) and numerically analysed by Wodzyński (2019)

$$
a=a\left(\frac{z}{\lambda}\right)=-e^{-A_{K}{ }^{-1} B_{K} \frac{z-\delta}{\lambda}} \frac{\sinh \left(A_{K}^{-1} \sqrt{\Delta_{K}} \frac{z-\delta}{\lambda}\right)}{\sinh \left(A_{K}^{-1} \sqrt{\Delta_{K}} \frac{\delta}{\lambda}\right)} a^{0}+e^{A_{K}^{-1} B_{K} \frac{z-\delta}{\lambda}} \frac{\sinh \left(A_{K}^{-1} \sqrt{\Delta_{K}} \frac{z}{\lambda}\right)}{\sinh \left(A_{K}^{-1} \sqrt{\Delta_{K}} \frac{\delta}{\lambda}\right)} a^{\delta}
$$

Note that in Eq. (11) $\sqrt{\Delta_{K}}$ for $\Delta_{K}=S_{K}^{2}-A_{K}\{A\}_{K}$ is defined as a unique positive matrix for which ${\sqrt{\Delta_{K}}}^{2}=\Delta_{K}$ and $A_{K}^{-1} \sqrt{\Delta_{K}}=\sqrt{\Delta_{K}} A_{K}^{-1}$ and $A_{K}^{-1} B_{K}=B_{K} A_{K}^{-1}$ hold under properties of the matrix $A_{K}, B_{K}$ and $C_{K}$. We are to debark from Eq. (11) $\omega_{\text {exp }}\left(\varphi^{1}\right), \omega_{\text {exp }}\left(\varphi^{2}\right), \omega_{r o t}\left(\varphi^{1}\right)$ and $\omega_{\text {rot }}\left(\varphi^{2}\right)$.

Case $1^{\circ}$ Pair $\left(\varphi^{1}, \varphi^{2}\right)$ consists of left and right even Fourier fluctuations. In this case $\varphi^{1}=\varphi_{L}, \varphi^{2}=\varphi_{R}, \beta=0$ and hence Eq. (11) reduces to

$$
\begin{aligned}
& a_{1}=-\frac{\sinh \left[\omega_{\text {exp }}\left(\varphi^{1}\right) \frac{z-\delta}{\lambda}\right]}{\sinh \left[\omega_{\text {exp }}\left(\varphi^{1}\right) \frac{\delta}{\lambda}\right]} a_{1}(0)+\frac{\sinh \left[\omega_{\text {exp }}\left(\varphi^{1}\right) \frac{z}{\lambda}\right]}{\sinh \left[\omega_{\text {exp }}\left(\varphi^{1}\right) \frac{\delta}{\lambda}\right]} a_{1}(\delta) \\
& a_{2}=-\frac{\sinh \left[\omega_{\text {exp }}\left(\varphi^{2}\right) \frac{z-\delta}{\lambda}\right]}{\sinh \left[\omega_{\text {exp }}\left(\varphi^{2}\right) \frac{\delta}{\lambda}\right]} a_{2}(0)+\frac{\sinh \left[\omega_{\text {exp }}\left(\varphi^{2}\right) \frac{z}{\lambda}\right]}{\sinh \left[\omega_{\text {exp }}\left(\varphi^{2}\right) \frac{\delta}{\lambda}\right]} a_{2}(\delta)
\end{aligned}
$$

under $r_{1,2}\left(\varphi^{1}\right)=\omega_{\text {exp }}\left(\varphi^{1}\right) \pm j \omega_{r o t}\left(\varphi^{1}\right), r_{1,2}\left(\varphi^{2}\right)=\omega_{\text {exp }}\left(\varphi^{2}\right)+j \omega_{r o t}\left(\varphi^{2}\right)$ for $\omega_{r o t}\left(\varphi^{1}\right)=0, \omega_{r o t}\left(\varphi^{2}\right)=0$ and

$$
\omega_{\text {exp }}\left(\varphi^{1}\right)=\sqrt{\frac{\langle k\rangle_{H}}{\langle k\rangle} \frac{\gamma_{1}}{\alpha_{1}}}, \omega_{\text {exp }}\left(\varphi^{2}\right)=\sqrt{\frac{\langle k\rangle_{H}}{\langle k\rangle} \frac{\gamma_{2}}{\alpha_{2}}}
$$

are exponential intensity the same for both fluctuations $\varphi^{1}=\varphi_{L}, \varphi^{2}=\varphi_{R}$, i.e. $\gamma_{1} / \alpha_{1}=\gamma_{2} / \alpha_{2}$. 
Case $2^{\circ}$ Pair $\left(\varphi^{1}, \varphi^{2}\right)$ consists of one even and one odd fluctuation. In this case $\varphi^{1}=\varphi_{L}, \varphi^{2}=\varphi_{O D D}, d \neq 0, \gamma_{1} / \alpha_{1}$ $\neq \gamma_{2} / \alpha_{2}$ (Kula, 2016; Wodzyński, 2019) and hence Eq. (11) reduces to the system of two second-order ordinary differential equations which imply single fourth-order differential equation

$$
\frac{d^{4} \chi}{d z^{4}}+\frac{1}{\lambda^{2}}\left(\frac{4 \beta^{2}}{\alpha_{1} \alpha_{2}}-\frac{\langle k\rangle_{H}}{\langle k\rangle}\left(\frac{\gamma_{1}}{\alpha_{1}}+\frac{\gamma_{2}}{\alpha_{2}}\right)\right) \frac{d^{2} \chi}{d z^{2}}+\frac{1}{\lambda^{4}}\left(\frac{\langle k\rangle_{H}}{\langle k\rangle}\right)^{2} \frac{\gamma_{1} \gamma_{2}}{\alpha_{1} \alpha_{2}} \chi=0
$$

satisfying by both amplitudes $a_{1}$ and $a_{2}$, i.e. for $\chi(z)=a_{1}(\lambda z)$ and $\chi(z)=a_{2}(\lambda z)$. The equation, characteristic for Eq. (14), is biquadratic:

$$
r^{2}+\frac{1}{\lambda^{2}}\left(\frac{4 \beta^{2}}{\alpha_{1} \alpha_{2}}-\frac{\langle k\rangle_{H}}{\langle k\rangle}\left(\frac{\gamma_{1}}{\alpha_{1}}+\frac{\gamma_{2}}{\alpha_{2}}\right)\right) r+\frac{1}{\lambda^{4}}\left(\frac{\langle k\rangle_{H}}{\langle k\rangle}\right)^{2} \frac{\gamma_{1} \gamma_{2}}{\alpha_{1} \alpha_{2}}=0, r=R^{2}
$$

Setting

$$
\Delta \equiv \frac{1}{\lambda^{4}}\left[\frac{4 \beta^{2}}{\alpha_{1} \alpha_{2}}-\frac{\langle k\rangle_{H}}{\langle k\rangle}\left(\frac{\gamma_{1}}{\alpha_{1}}+\frac{\gamma_{2}}{\alpha_{2}}\right)\right]^{2}-4 \frac{1}{\lambda^{4}}\left(\frac{\langle k\rangle_{H}}{\langle k\rangle}\right)^{2} \frac{\gamma_{1} \gamma_{2}}{\alpha_{1} \alpha_{2}}
$$

we arrive at the four complex roots of the characteristic for Eq. (15)

$$
r= \pm \omega_{\text {exp }} \pm j \omega_{\text {rot }}, \omega_{\text {exp }}>0, \omega_{r o t}>0
$$

in which positive reals $\omega_{\text {exp }}>0$ and $\omega_{\text {rot }}>0$ are interpreted as exponential intensity $\omega_{\text {exp }}=\omega_{\text {exp }}\left(\varphi_{L}\right)=\omega_{\text {exp }}\left(\varphi_{\text {ODD }}\right)$ and rotational intensity $\omega_{\text {rot }}=\omega_{\text {rot }}\left(\varphi_{L}\right)=\omega_{\text {rot }}\left(\varphi_{O D D}\right)$ of both Fourier fluctuations - left even $\varphi_{L}$ and odd $\varphi_{O D D}$. The exponential intensity $\omega_{\text {exp }}$ depends on the resistance of the conductor and on the rate at which fluctuations decline. Rotational intensity $\omega_{\text {rot }}$ expresses the oscillation rate of Fourier fluctuations. The exponential and rotational intensities can be calculated using the formulas:

$$
r= \pm \sqrt{\frac{1}{2}\left\{\frac{1}{\lambda^{2}} \frac{\langle k\rangle_{H}}{\langle k\rangle}\left[\left(\frac{\gamma_{1}}{\alpha_{1}}+\frac{\gamma_{2}}{\alpha_{2}}\right)-\frac{4 \beta^{2}}{\alpha_{1} \alpha_{2}}\right]+\sqrt{\Delta}\right\}} \text { for } \Delta \geq 0
$$

and

$$
\begin{gathered}
\omega_{\text {exp }}=\frac{1}{2} \sqrt{\frac{1}{\lambda^{2}}\left(\frac{\langle k\rangle_{H}}{\langle k\rangle}\left(\frac{\gamma_{1}}{\alpha_{1}}+\frac{\gamma_{2}}{\alpha_{2}}\right)-\frac{4 \beta^{2}}{\alpha_{1} \alpha_{2}}\right)+\sqrt{\left[\frac{1}{\lambda^{2}}\left(\frac{4 \beta^{2}}{\alpha_{1} \alpha_{2}}-\frac{\langle k\rangle_{H}}{\langle k\rangle}\left(\frac{\gamma_{1}}{\alpha_{1}}+\frac{\gamma_{2}}{\alpha_{2}}\right)\right]^{2}-\Delta\right.}} \\
\omega_{\text {rot }}=\sqrt{\frac{-\Delta}{\frac{1}{\lambda^{2}}\left(\frac{\langle k\rangle_{H}}{\langle k\rangle}\left(\frac{\gamma_{1}}{\alpha_{1}}+\frac{\gamma_{2}}{\alpha_{2}}\right)-\frac{4 \beta^{2}}{\alpha_{1} \alpha_{2}}\right)+\sqrt{\left[\frac{1}{\lambda^{2}}\left(\frac{4 \beta^{2}}{\alpha_{1} \alpha_{2}}-\frac{\langle k\rangle_{H}}{\langle k\rangle}\left(\frac{c_{1}}{\alpha_{1}}+\frac{c_{2}}{\alpha_{2}}\right)\right)\right]^{2}-\Delta}}}
\end{gathered}
$$

for $\Delta \leq 0$ 
If in Eq. (18) the expression under the external root is non-negative, then Eq. (18) shows the exponential intensity for $\Delta \geq 0$ as well as the rotational intensity, which in this case is equal to zero. However, if the expression under the root is negative then Eq. (18) expresses two conjugated imaginary numbers - one imaginary part is positive, the other negative. The positive imaginary part is the rotational intensity for $\Delta \geq 0$. It is practically impossible to prove the hypothesis by analytical methods. The workable method is the use of numerical methods, which are similar to fundamental ideas, e.g. to the finite differences method (FDM). The mentioned ideas are used in programs preparing various graphs by introducing a points grid, in which the corresponding function values are calculated. It should be noted that in the analysed case, it is practically impossible to find extreme points of both intensities by analytical methods since the formulas contain operations on the real and imaginary parts of complex roots of the biquadratic equation (Figs. 3-6).

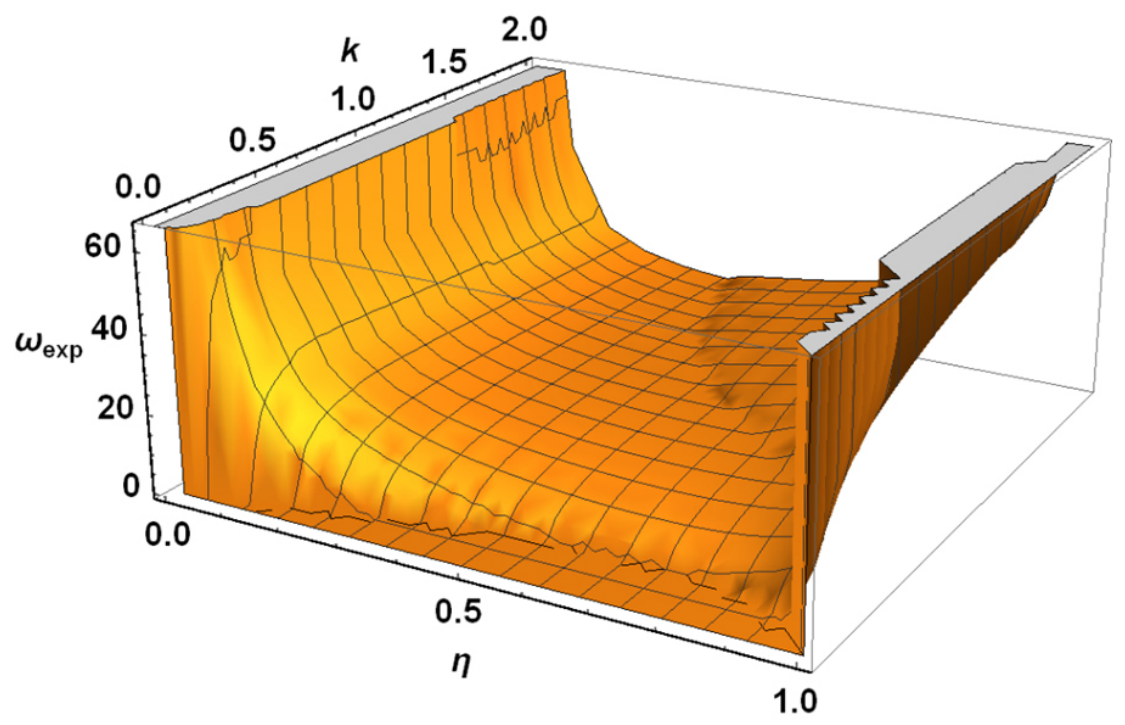

Fig. 3. Exponential intensity for the pair of impulses $f_{L}, f_{O D D}$

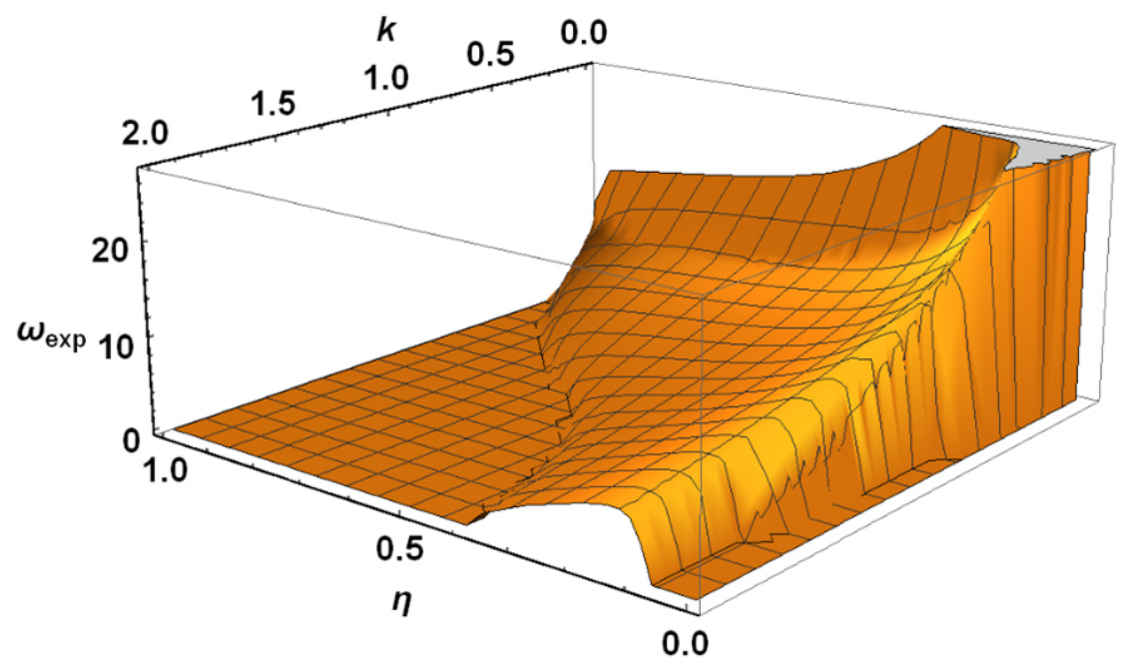

Fig. 4. Rotational intensity for the pair of impulses $f_{L}, f_{O D D}$ 


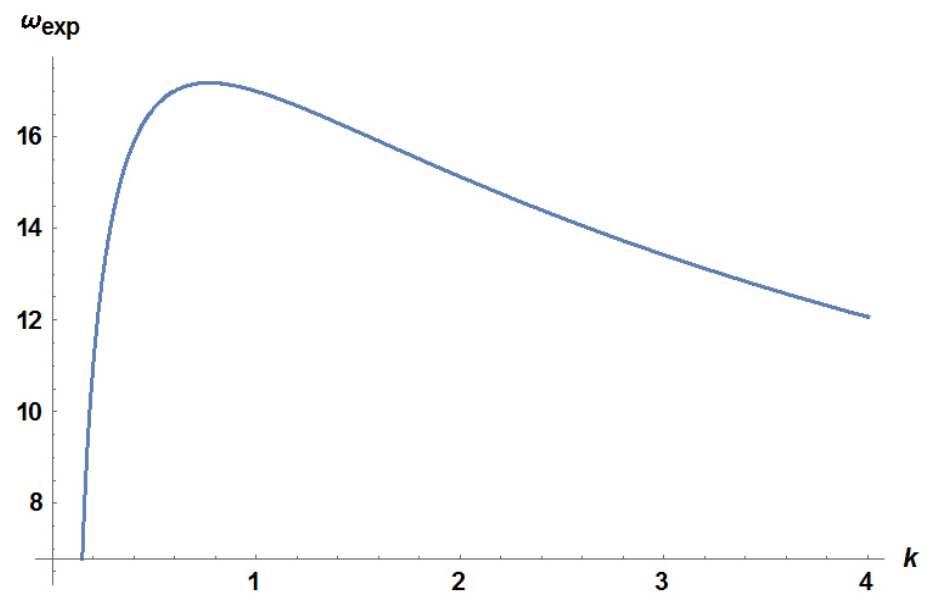

Fig. 5. Exponential intensity for the pair of impulses $f_{L}, f_{O D D}$ given in Eq. (12) at $\eta=0.25$

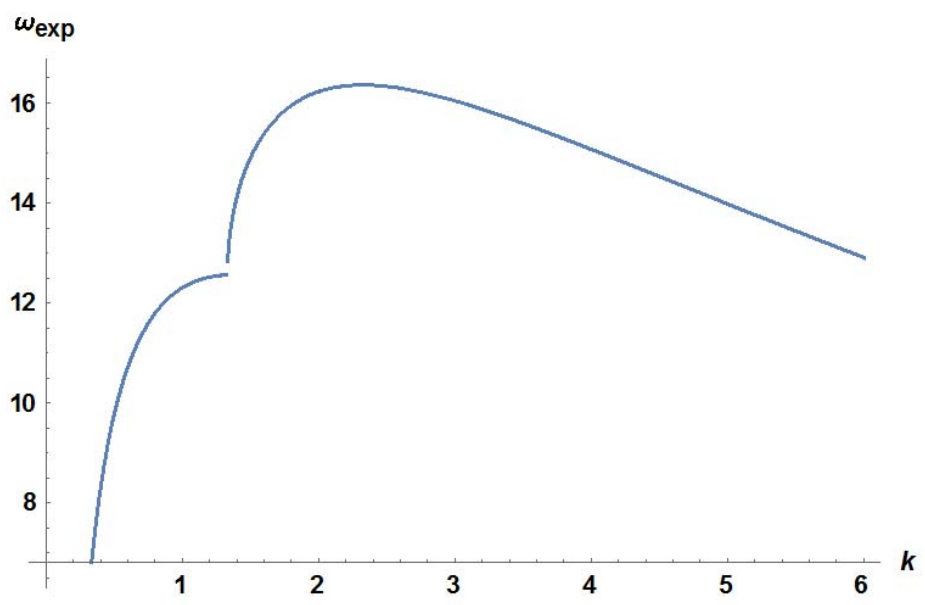

Fig. 6. Exponential intensity for the pair of impulses $f_{L}, f_{O D D}$ given in Eq. (12) at $\eta=0.5$

The line presented as an exponential intensity in Figure 6 has a small gap in which the one-side limit of the intensity is infinite (a similar situation occurs for the curve $y=\sqrt{x}$ at point $x=0$ ).

\section{CONCLUDING REMARKS}

Considerations in this paper are restricted to the modelling of the boundary effect phenomenon in the framework of thermal conductivity based on the Fourier conductivity law. The above understanding of the boundary effect phenomenon was analyzed in several research papers that use methods similar to the tolerance averaging technique (Szlachetka \& Wągrowska, 2011; Witkowska-Dobrev \& Wągrowska, 2015; Kula, 2016; Kula, Wierzbicki \& Witkowska-Dobrev, 2018; Wodzyński, Kula \& Wierzbicki, 2018; Kula, 2019). However, original tolerance modelling only allows for approximate analysis of physical phenomena occurring in periodic composites. The emergence of a variant of tolerance modelling equations in the literature allowing for equivalent reformulation of equations of mechanics for periodic composites, i.e. surface localized equations, has become the strong 
motivation for undertaking research on the boundary effect phenomenon in composites and it was found that boundary fluctuations encounter not only intense exponential damping, but also so-called rotational damping when traveling through composite media. The article deals with the analysis of these two types of attenuation. Appropriate formulas were derived and used in the paper for these two types of intensity in the selected cases of fluctuating boundary loads. The formula for the exponential intensity $\omega_{\exp }$ in the case of a single fluctuation (even as well as odd) is the root of the function of two variables: saturation $\eta$ with the first component of the composite and the quotient $k$ of two component conductivities. It also depends on the scale parameter $\lambda$. From a formal point of view, here in the boundary localized approach, the dependence on the conductivity quotient is a square root of two linear functions ratio (Kula, 2019). Therefore, the partial derivative of the exponential intensity in relation to the conductivity quotient is either positive or negative everywhere. It means that locally, i.e. in a sufficiently small neighborhood of any $\eta \in(0,1)$, there is the implicit function $k(\eta)$ mentioned in the hypothesis (Kula, 2019). Thus, it should be recognized that in the case of a single fluctuation there is analytical evidence of the hypothesis formulated in the paper.

The existence of critical points of the functions $\omega_{\text {exp }}(\eta, k)$ and $\omega_{\text {rot }}(\eta, k)$ is proved in the paper. However, this result only applies to the fluctuation pairs for which the system of two second-order ordinary differential equations is reduced to a single fourth-order equation are numerically discussed. In the mentioned case $\omega_{\text {exp }}(\eta, k)$ and $\omega_{\text {rot }}(\eta, k)$ are real and imaginary parts of the complex root of the corresponding biquadratic equation. In the mentioned case, realization of analytical procedures seems to be difficult to implement. Hence, the hypothesis formulated in the paper can only be verified numerically (cf. Wodzyński, 2019). Such numerical verification in the form of graphic illustrations resulting from the use of computer programs was partially carried out in the analyzed cases - a pair of even and odd Fourier fluctuations; a pair of even and odd modified Fourier fluctuations; and a pair of fluctuations with infinite amplitudes. The latter case is of significant importance in mechanics and in particular in civil engineering - it is an indication of the family of fluctuations posing a relatively low risk of destruction to precise electronic devices located in rooms whose walls are built of composite materials. In this case, the limit value of rotational intensity is zero, and the exponential damping can be controlled by the saturation values of the composite components. The analysis of transfer intensity through the region of a two-phase unidirectional-periodic composite of selected boundary fluctuations is the original element of the paper (Wodzyński, 2019). Term homogeneous periodicity used in the paper for periodicity determined by a constant period vector suggests that in many cases of periodicity it can be interpreted as a homogeneous periodicity by appropriate selection of "heterogeneous cell coverage" of the region occupied by the composite media despite the inclusion distribution appearing to be non-periodic. However, these situations still require further investigation.

\section{REFERENCES}

Kula, D. (2014). On Fourier implementation of tolerance modeling of linear elastodynamics of periodic composites. Journal of Applied Mathematics and Computational Mechanics, 13 (4), 73-80.

Kula, D. (2016). Fourier variant homogenization of the heat transfer processes in periodic composites (doctoral thesis, Łodz University of Technology, Łódź, Poland).

Kula, D. (2019). On the damping intensity of the odd Fourier impulse loading the boundary of the periodic composite. Scientific Review Engineering and Environmental Sciences, 3, 321-331.

Kula, D. \& Wierzbicki, E. (2019). Surface localized heat transfer in periodic composites. Acta Mechanica et Automatica, 13 (2), 124-129.

Kula, D., Wierzbicki, E. \& Witkowska-Dobrev, J. (2018). Fourier variant homogenization treatment of single impulse boundary effect behaviour. Mechanics and Mechanical Engineering, 22 (3), 683-690.

Ostrowski, P. P. (2017). Tolerance modelling of Thermomechanics in microstructured media. Łódz: Lodz University of Technology Press. 
Kula, D., Wodzyński, Ł. (2020). Transfer of thermal fluctuations through the building partition formed by periodic composite material. Acta Sci. Pol. Architectura, 19 (1), 21-30. doi: 10.22630/ASPA.2020.19.1.3

Szlachetka, O. \& Wągrowska, M. (2011). Efekt brzegowy w warstwowej przegrodzie o podłużnej gradacji własności. Acta Sci. Pol. Architectura, 10 (3), 27-34.

Wierzbicki, E. (2019). Averaging techniques in thermomechanics of composite solids. Surface localization versus Tolerance Aceraging. Warsaw: Warsaw University of Life Sciences Press.

Witkowska-Dobrev, J. \& Wagrowska, M. (2015). Zasięg efektu warstwy brzegowej w kompozytach warstwowych dla zagadnień elastostatyki. Acta Sci. Pol. Architectura, 14 (2), 19-30.

Wodzyński, Ł. (2019). Przenoszenie fluktuacji termicznych przez przegrodę budowlana utworzona z periodycznego materiatu kompozytowego [Transfer of thermal fluctuations through a building partition formed of periodic composite material] (doctoral thesis Szkoła Główna Gospodarstwa Wiejskiego w Warszawie, Warszawa, Poland).

Wodzyński, Ł., Kula, D. \& Wierzbicki, E. (2018). Transport of temperature fluctuations across a two-phased laminate conductor. Mechanics and Mechanical Engineering, 22 (3), 775-787.

Woźniak, C. \& Wierzbicki, E. (2000). Averaging techniques in thermomechanics of composite solids. Tolerance Averaging versus Homogenization. Częstochowa: Częstochowa University of Technology Press.

\section{PRZENOSZENIE FLUKTUACJI TERMICZNYCH PRZEZ PRZEGRODĘ BUDOWLANA UTWORZONA Z PERIODYCZNEGO KOMPOZYTU}

\section{STRESZCZENIE}

W pracy przedstawiono przykłady fluktuacji termicznych, które są intensywnie thumione przez przegrodę budowlaną utworzoną z jednokierunkowego periodycznego dwufazowego kompozytu. To intensywne thumienie dotyczy nie tylko tłumienia wykładniczego, do niedawna utożsamianego z tzw. zjawiskiem efektu brzegowego, ale także tłumienia oscylacyjnego, które obok tłumienia wykładniczego najczęściej także towarzyszy zjawisku efektu brzegowego. Rozważania ograniczono do parabolicznego równania przewodnictwa cieplnego i jego równoważnego, ale można je łatwo przenieść na przykład do liniowej sprężystości liniowej i do opisu innych zjawisk fizycznych występujących w kompozytach. Rozważania mogą znaleźć zastosowanie przy projektowaniu pomieszczeń, które powinny szczególnie skutecznie chronić precyzyjne urządzenia elektroniczne przed szkodliwym wpływem wahań zewnętrznych pól fizycznych.

Słowa kluczowe: skuteczne przewodzenie ciepła, zjawisko efektu brzegowego, przegroda budowlana, średnia temperatura pola 